\title{
Administration of $\boldsymbol{\beta}_{\mathbf{2}}$-Adrenergic Agonists During the Peri-Implantation Period Does Not Improve Implantation or Pregnancy Rates in Intracytoplasmic Sperm Injection (ICSI) Cycles
}

\author{
Osni L. Pinheiro, ${ }^{1,2}$ Mario Cavagna,,${ }^{3,4}$ Ricardo L. R. Baruffi, ${ }^{3}$ Ana L. Mauri, ${ }^{3}$ \\ Claudia Petersen, ${ }^{3}$ and José G. Franco Jr. ${ }^{3,5,6}$
}

Submitted January 14, 2003; accepted October 21, 2003

\begin{abstract}
Purpose: The objective of the present investigation was to determine implantation and pregnancy rates in patients undergoing ICSI and treated with $\beta_{2}$-adrenergic agonists, considering the uterine-relaxing action of these agents.

Methods: A total of 225 women undergoing ICSI at the Center for Human Reproduction, "Sinhá Junqueira" Maternity Foundation, entered the study. Patient participation in each group was random, by drawing lots, using a randomization table previously elaborated for the study (2:2:1). The group I (90 women) received $10 \mathrm{mg}$ of terbutaline daily for 15 days starting on the day of oocyte retrieval; group II ( 90 women) received $20 \mathrm{mg}$ of ritodrine daily during the same period of time as group I; group III (45 patients) received no treatment and was used as control. The evaluation was interrupted in 3 patients of group I and in 30 patients of group II because of a high incidence of side effects.

Results: Pregnancy, implantation, and miscarriage rates were not significantly different ( $p>$ 0.05 ) between the three groups: $29.88 \%, 13.25 \%$, and $26.9 \%$ for group I; $33.33 \%, 17.5 \%$, and $10.0 \%$ for group II; $28.88 \%, 15.07 \%$, and $15.38 \%$ for group III, respectively.

Conclusions: The results of this study do not support the routine use of $\beta_{2}$-adrenergic agonists during the peri-implantation period in assisted reproductive technology cycles.
\end{abstract}

KEY WORDS: ICSI; implantation rates; ritodrine; terbutaline; uterine contractility.

\section{INTRODUCTION}

The most important purpose of assisted reproductive techniques (ART) is to place a single euploid embryo in the uterus to achieve successful implantation and a normal pregnancy, which will result in a healthy

\footnotetext{
${ }^{1}$ Department of Gynecology and Obstetrics, Faculty of Medicine of Botucatu (UNESP), Botucatu, Brazil.

${ }^{2}$ Department of Physiological Science, Faculty of Medicine of Marília, Marília, Brazil.

${ }^{3}$ Center for Human Reproduction, Sinhá Junqueira Maternity Foundation, Ribeirão Preto, Brazil.

${ }^{4}$ Postgraduation Program of Maternal-Fetal Health, University of Santo Amaro, São Paulo, Brazil.
}

offspring. Nevertheless, it is important to emphasize that clinical implantation in humans is successful in a maximum of $30 \%$ of cases (1) and almost $90 \%$ of the embryos produced by ART and transferred to the uterus fail to implant $(2,3)$. Implantation involves complex interactions and a series of steps leading to an effective communication between the embryo and the endometrium. Many factors may create

\footnotetext{
${ }^{5}$ Department of Gynecology and Obstetrics, University of Ribeirão Preto, (UNAERP), Ribeirão Preto, Brazil.

${ }^{6}$ To whom correspondence should be addressed at Rua D. Alberto Gonçalves, 1500-CEP 14085-100, Riberirão Preto, São Paulo,
} Brazil; e-mail: crh@crh.com.br and franco@crh.com.br. 
an environment unfavorable to embryo implantation due to morphological and biochemical alterations of the endometrium caused by ovarian hormones (4-8). Moreover, it is possible that the high estrogen levels obtained after controlled ovarian hyperstimulation may increase uterine contractility, which has been proposed as a potential etiological mechanism in implantation failure (9-12). In addition, the techniques of transferring embryos to the uterus may promote uterine contractions, particularly if difficulty is found in passing the catheter through the cervix or the catheter touches the uterine fundus (10). Fanchin et al. (13) postulated that vaginal progesterone administration starting on the day of oocyte retrieval may reduce uterine contractions and improve implantation rates by avoiding the displacement of embryos from the uterine cavity. The use of $\beta_{2}$-adrenergic agonists, which have a relaxing action on uterine muscle, may be useful for this purpose. Recently, Tsirigotis et al. (14) studied the effects of ritodrine administration at peri-implantation time and concluded that implantation rates may be improved with this approach.

The objective of this investigation was to determine implantation and pregnancy rates in patients undergoing ICSI who were treated with two types of $\beta_{2}$ adrenergic agonists (terbutaline and ritodrine) during the peri-implantation period.

\section{MATERIALS AND METHODS}

A total of 225 women undergoing ICSI at the Center for Human Reproduction, "Sinhá Junqueira" Maternity Foundation, entered the study. The indication for ICSI was male infertility defined according to the recommendations of the World Health Organization except for sperm morphology ( $<14 \%$ normal sperm, strict criteria). Patient participation in each group was random, by draw of lots, using a randomization table previously elaborated for the study (2:2:1). The group I (90 women) received $10 \mathrm{mg}$ of terbutaline daily P.O. for 15 days starting on the day of oocyte retrieval; group II (90 women) received $20 \mathrm{mg}$ of ritodrine P.O. daily during the same period of time as group I; group III (45 patients) received no treatment and was used as control. The evaluation was interrupted in three patients of Group I and in 30 patients of Group II due to a high incidence of side effects.

All patients were treated according to a long protocol with a gonadotrophin releasing hormone agonist (Synarel ${ }^{\circledR}$, Searle, Brazil) followed by a fixed ovarian stimulation regimen consisting of 300 IU of daily re- combinant FSH (Puregon ${ }^{\circledR}$, Organon, Brazil); 10,000 IU of human chorionic gonadotrophin (Pregnyl ${ }^{\circledR}$, Organon, Brazil) was given when two or more follicles measured $\geq 17 \mathrm{~mm}$, and oocyte retrieval was carried out 34-36 h later. Cumulus and corona cells of the oocytes were removed by enzymatic digestion with hyaluronidase (Sigma Chemical Co, St Louis, MO, USA) and oocytes at metaphase II of the second meiotic division were subjected to ICSI, which was carried out on the heated stage of an inverted microscope (Eclipse TE 300, Nikon, Japan), employing automatic manipulators (NT-88, Narishige, Japan) and microinjectors (IM-16, Narishige, Japan).

Up to three embryos were transfered into the uterine cavity after $40-42 \mathrm{~h}$ of after intracytoplasmic insemination. The frequency of uterine contractions was not realized prior to embryo transfer. Luteal phase supplementation was performed with intravaginal micronized progesterone (Utrogestan ${ }^{\circledR}$, Enila, Brazil) $800 \mathrm{mg}$ daily, starting on the day of embryo transfer. A serum $\beta$-hCG test was performed 14 days after embryo transfer. Vaginal ultrasonography was carried out 14 days after the positive $\beta$-hCG result to determine the number and viability of gestation sacs.

The results obtained for the three groups were compared by the Chi square test for trend, with the level of significance set at $p<0.05$.

\section{RESULTS}

Patient's age did not differ significantly $(p>0.05)$ between groups: $34.6 \pm 0.49$ in the terbutaline group (group I), $33.35 \pm 0.69$ in the ritodrine group (group II), and $34.71 \pm 0.68$ in the control group (group III). The number of oocytes retrieved and the number of mature oocytes (MII) did not differ significantly $(p>0.05)$ between the three groups: $11.30 \pm 0.78$ and $9.18 \pm 0.64$ in group I; $11.60 \pm 0.81$ and $9.78 \pm 0.71$ in group II; $11.13 \pm 0.94$ and $9.22 \pm 0.75$ in group III. There were not significant differences in the number of embryos transferred in each of the three groups: $2.86 \pm 0.11$ in group I, $2.67 \pm 0.13$ in group II, and $2.80 \pm 0.14$ in group III $(p>0.05)$. Pregnancy and implantation rates did not differ significantly $(p>0.05)$ between the three groups: $29.88 \%$ and $13.25 \%$ in group I, $33.33 \%$ and $17.5 \%$ in group II, and $28.88 \%$ and $15.07 \%$ in group III, respectively. Also, no significant differences in miscarriage rates were observed between groups I, II, and III, with respective values of $26.9 \%, 10.0 \%$, and $15.38 \%(p>0.05)$. The results are summarized in Table I. 
Table I. Summary of the Results Obtained for the Three Groups

\begin{tabular}{lccc}
\hline \multicolumn{1}{c}{ Parameter } & Group I-terbutaline $(n=87)$ & Group II-ritodrine $(n=60)$ & Group III—control $(n=45)$ \\
\hline Maternal age & $34.6 \pm 0.49^{*}$ & $33.35 \pm 0.69^{*}$ & $34.71 \pm 0.68^{*}$ \\
Oocytes retrieved & $11.3 \pm 0.78^{*}$ & $11.6 \pm 0.81^{*}$ & $11.13 \pm 0.94^{*}$ \\
Mature oocytes & $9.18 \pm 0.64^{*}$ & $9.78 \pm 0.71^{*}$ & $9.22 \pm 0.75^{*}$ \\
Fertilization rate (\%) & $65.61^{*}$ & $73.12^{*}$ & $68.57^{*}$ \\
Embryos transferred & $249(2.86 \pm 0.11)^{*}$ & $160(2.67 \pm 0.13)^{*}$ & $126(2.80 \pm 0.14)^{*}$ \\
Gestational sacs & 33 & 28 & 19 \\
Pregnancy rate (\%) & $29.88(26 / 87)^{*}$ & $33.33(20 / 60)^{*}$ & $28.88(13 / 45)^{*}$ \\
Implantation rate (\%) & $13.25(33 / 249)^{*}$ & $17.5(28 / 160)^{*}$ & $15.07(19 / 126)^{*}$ \\
Miscarriage rate (\%) & $26.92(7 / 26)^{*}$ & $10(2 / 20)^{*}$ & $15.38(2 / 13)^{*}$ \\
\hline
\end{tabular}

*No significant difference $(p>0.05)$.

\section{DISCUSSION}

Uterine contractions at the time of embryo transfer may adversely affect the outcome of assisted reproductive procedures. Lesny et al. (10) studied the frequency of uterine contractions in a simulation of embryo transfer in 14 women, using a catheter with $30 \mu \mathrm{L}$ of a galactose-based echo-enhancing agent for contrast (Echovis ${ }^{\circledR}$, Schering, UK) to represent embryos and transfer medium. These authors performed ET without touching the uterine fundus with the catheter, and these were considered easy ET. In another group of patients, to simulate a difficult ET, the uterine fundus was touched deliberately twice with the end of the catheter. There were no uterine contractions in the group of easy ET, and Echovist ${ }^{\circledR}$ remained in the upper part of the uterus for at least $45 \mathrm{~min}$. On the other hand, vigorous uterine contractions were recorded in the group of difficult ET, with the contrast being displaced in six of the seven patients. It has also been postulated that endometriosis may have an adverse effect on implantation because the women affected by this disease have a significantly higher uterine contraction frequency (15). Fanchin et al. (16) investigated the importance of uterine contractility in the process of implantation. These authors compared the frequency of uterine contractions at the time of embryo transfer 4 days after hCG (embryos with 4-8 cells) and 7 days after hCG (blastocyst stage), and concluded that the uterus reaches quiescence 7 days after hCG administration, so that implantation rates could be higher at that time. Another possibility to decrease uterine contractility during the peri-implantation period could be the use of $\beta_{2}$-adrenergic agonists such as ritodrine and terbutaline, which promote relaxation of human myometrial muscle by their action on $\beta_{2}$-adrenergic receptors (17-20). Tsirigotis et al. (14) reported that ritodrine administration during the peri-implantation period improves pregnancy and implantation rates.
These authors obtained implantation and pregnancy rates of $4.2 \%$ and $16.7 \%$ in the control group, as opposed to significantly higher rates of $14.8 \%$ and $46.7 \%$, respectively, in the group treated with ritodrine. Our investigation was designed to study the effects of two $\beta_{2}$-adrenergic agonists, ritodrine and terbutaline, on pregnancy and implantation rates of ICSI cycles. Our observations were divergent from those of Tsirigotis et al., in our study the pregnancy and implantation rates were not significantly different among the control group, the group treated with ritodrine and the group treated with terbutaline. The same dose of ritodrine was used in both investigations. In our study, the group using ritodrine was smaller than the group using terbutaline. Side effects such as palpitation and tremor were more evident with ritodrine, and led us to limit this group. One important difference between the two investigations was that our patient series was larger than that of Tsirigotis et al. However, the acceptance of a $H_{0}$ Hypothesis (no difference between groups) when the hypothesis in reality is false would induce a so called type II error ( $\beta$-error) and to avoid this type of error it is advisable to increase the number of patients studied. To detect a difference in the pregnancy rates between the two treatment groups (keeping the current rates in both groups), with a power of $80 \%$ and significance level of $5 \%$, a total of 32.220 of each group were required for terbutaline group and 1371 for ritodrine group. It should also be emphasized that implantation and pregnancy rates in the control group of the series reported by Tsirigotis et al. were very low, in contrast to our results and to the results reported in the literature $(21,22)$. In the investigation by Tsirigotis et al. it was not clear if the groups studied were formed by patients with increased uterine activity, which could explain the low implantation rates achieved in the control group. In our study we did not monitor the frequency of uterine contractions prior 
to embryo transfer; therefore, it is possible that the use of $\beta_{2}$-adrenergic agonists may improve implantation rates in selected women who have increased uterine contractions during the peri-implantation period. It is important to note that uterine contractions may be promoted by the transfer procedure, mainly when there are difficulties in performing it $(10,23)$. To improve implantation rates in patients with increased uterine contractility, further clarification of the role of $\beta_{2}$-adrenergic agonists in this group of patients is needed; in this situation, whether or not administration of these drugs is effective in improving implantation rates remains to be demonstrated. In conclusion, the results of our study do not support the routine use of $\beta_{2}$-adrenergic agonists during the peri-implantation period of assisted reproductive technology cycles.

\section{REFERENCES}

1. Miller JF, Williamson E, Glue J: Fetal loss after implantation. Lancet 1980;ii:554-556

2. Simón C, Garcia Velasco JJ, Valbuena D, Peinado JA, Moreno $\mathrm{C}$, Remohi J, Pellicer A: Increasing uterine receptivity by decreasing estradiol levels during the preimplantation period in high responders with the use of a follicle-stimulating hormone step-down regimen. Fertil Steril 1998;70:234-239

3. Gregory L: Ovarian markers of implantation potential in assisted reproduction. Hum Reprod 1998;13(Suppl. 4):117132

4. Fanchin R, Righini C, Jean-Marc A, Olivennes F, Ziegler D, Frydman R: New look at endometrial echogenicity: Objective computer-assisted measurements predict endometrial receptivity in in vitro fertilization-embryo transfer. Fertil Steril 2000;74:274-281

5. Tang B, Gurpide E: Direct effect of gonadotrophins on decidualization of human endometrial stroma cells. J Steroid Biochem Mol Biol 1993;47:115-121

6. Paulson RJ, Sauer MV, Lobo RA: Embryo implantation after human in-vitro fertilization: Importance of endometrial receptivity. Fertil Steril 1990;53:870-874

7. Fanchin R, Righini C, Olivennes F, Ferreira AL, Ziegler D, Frydman R: Consequences of premature progesterone elevation on the outcome of in-vitro fertilization: Insights into a controversy. Fertil Steril 1997;68:799-805

8. Valbuena D, Jasper M, Remohí J, Pellicer A, Simón C: Ovarian stimulation and endometrial receptivity. Hum Reprod 1999;14(Suppl. 2):107-111
9. Lyons EA, Taylor PJ, Zheng XH, Ballard G, Levi CS, Kredentser JV: Characterization of subendometrial myometrial contractions throughout the menstrual cycle in normal fertile women. Fertil Steril 1991;55:771-774

10. Lesny P, Killick SR, Tetlow RL, Robinson J, Maguiness SD: Embryo transfer can we learn anything from the observation of junctional zone contractions? Hum Reprod 1998;13:15401546

11. Lesny P, Killick SR, Robinson J, Raven G, Maguiness SD: Junctional zone contractions and embryo transfer: Is it safe to use a tenaculum? Hum Reprod 1999;9:2367-2370

12. Fanchin R, Righini C, Olivennes F, Taylor S, Ziegler D, Frydman R: Uterine contractions at the time of embryo transfer alter pregnancy rates after in-vitro fertilization. Hum Reprod 1998;13:1968-1974

13. Fanchin R, Righini C, Ziegler D, Olivennes F, Ledée N, Frydman R: Effects of vaginal progesterone administration on uterine contractility at the time of embryo transfer. Fertil Steril 2001;75:1136-1140

14. Tsirigotis M, Pelekanos M, Gilhespié S, Gregorakis S, Pistofidis G: Ritodrine use during the peri-implantation period reduces uterine contractility and improves implantation and pregnancy rates post-IVF. In Abstracts of the 16th Annual Meeting of the ESHRE, O-024, Bologna, 2000.

15. Garcia-Velasco JA, Arici A: Is the endometrium or oocyte/embryo affected in endometriosis? Hum Reprod 1999;14(Suppl. 2):77-89

16. Fanchin R, Ayoubi JM, Righini C, Olivennes F, Schonauer LM, Frydman R: Uterine contractility decreases at the time of blastocyst transfer. Hum Reprod 2001;16:1115-1119

17. Caritis SN, Chiao JP, Moore JJ, Ward SM: Myometrial desensitization after ritodrine infusion. Am J Physiol 1987;253:E410 E417

18. Liu YL, Nwosu UC, Rice PJ: Relaxation of isolated myometrial muscle by beta 2 -adrenergic receptors but not beta 1adrenergic receptors. Am J Obstet Gynecol 1998;179:895-898

19. Kobayashi M, Takeda K, Murata S, Kojima M, Akahane M, Inoue Y, Kitamura K, Kawarabayashi F: Pharmacological characterization of KUR-1246, a selective uterine relaxant. J Pharmacol Exp Ther 2001;297:666-671

20. Dennedy MC, Houlihan DD, McMillan H, Morrison JJ: Beta 2and beta 3-adrenoreceptor agonists: Human myometrial selectivity and effects on umbilical artery tone. Am J Obstet Gynecol 2002;187:641-647

21. Assisted reproductive technology in the United States: 1996 results generated from the American Society for Reproductive Medicine/Society for Assisted Reproductive Technology Registry, Birmingham, Alabama. Fertil Steril 1999;71:798-807

22. Gutierrez-Najar A, Stern-Collin Y, Nunes J, Gonzalez-Panzzi ME, Orbea-Yravez M: Pregnancy and birth after assisted reproduction. Reprod Biomed Online 2002;5:78-88

23. Mansour RT, Aboulghar MA: Optimizing the embryo transfer technique. Hum Reprod 2002;7:1149-1153 